\title{
Poetics of Performing: Becoming a Mother
}

\author{
Lia da Rocha Lordelo ${ }^{1}$ (D)
}

Received: 13 March 2021 / Revised: 20 April 2021 / Accepted: 21 April 2021 / Published online: 10 May 2021 (c) The Author(s), under exclusive licence to Springer Nature Switzerland AG 2021

\begin{abstract}
In this article, I part from the argument developed by Valsiner in a text on pathways to development and education (Valsiner, 2008): he claims we need to move from the static ontology of being-which asks "what is X?" to the epistemology of becoming — which asks "what is $\mathrm{X}$ becoming." He then asks the consequent question: how to do empirical work on that new key? How to research on a crucial feature of human development-the self-reflexive intentional relating with the anticipated future? This article is an attempt to develop the epistemology of becoming on an empirical level, by analyzing my self-writings from the period I became a mother. I show that becoming a mother is a developmental process that happens through time and through the performing of daily activities such as nursing, bathing the baby and so on. In order to go beyond the study of the epistemology of becoming, I propose the poetics of performing.
\end{abstract}

Keywords Human development $\cdot$ Motherhood $\cdot$ Poetics $\cdot$ Performing

\section{A Developmental Problem Spotted: the Epistemology of Becoming}

In all issues pertaining to development and education the reliance on ontological discourse is misfitting. We are not interested in the ways of being of a child of age X or school grade P. Instead, we look at the child of age X as s/he is moving towards becoming a child of age $X+1$ (or of school grade $P+1$ ). When we characterise "what is" we think of "what is-becoming" (in case of development) and - in case of education - how that "what-is-becoming" might be directed towards specific meaningful (for the directing agent) an outcome state. Thus, educational and developmental theories need to break with the ontological conceptualizations that may be sufficient for the nondevelopmental sciences. Valsiner, 2008)

Development is basically change through time. Human development is basically us changing through time. The minute I write these words, I realize I have been drastically changingslowly but steady through the past 41 years-although I like to think of myself as a stable person who has not changed much.

Lia da Rocha Lordelo

lialordelo@gmail.com

1 Federal University of Recôncavo of Bahia, Santo Amaro, Bahia, Brazil 
That lesson - the lesson of change - has been beautifully constructed and taught by cultural psychologist Jaan Valsiner over the course of dozens, maybe hundreds of chapters and articles. In particular, development as the property of open systems to undergo qualitative transformations, under constant relating with the environment within irreversible time (Zittoun et al., 2013). Flexibility and open-endedness are crucial characteristics of that developmental process, and they are guaranteed by a shift in perspective: for Valsiner (2008), the reliance on an ontological discourse, both in psychology and in education, is misfitting. We must move from the static ontology of being — which asks "what is X?" to the epistemology of becomingwhich asks "what is X becoming," or yet, "how is X becoming Y?," or "How is X changing?." That question characterizes the very own nature of development. Once we start to deal with that problem, not only will we view development in a less normative, programmed way (da Rocha Lordelo, 2017), but we will also need to think of different techniques and methods to study it, as well as theories to describe it. In that sense, cultural psychology has been increasingly viewed as a multidisciplinary field on the crossroads between psychology, semiotics, and cultural studies focusing on how individuals make their experiences meaningful (Cabell \& Valsiner, 2014). That scenario enables us researchers to defy already established theories and methods within psychological science.

But the notion at stake, here, is specifically that of development. After stating that the problem we face must be the shift of focus from the ontology of being to the epistemology of becoming, Valsiner adds that the real question is, how to find ways of doing empirical work which accounts for becoming? That question needs to take into consideration, according to him, a crucial feature of the specifically human level of development: a selfreflexive intentional relating with the anticipated future (Valsiner, 2008).

\section{Poetics of Performing: a Developmental Process}

So I part now from the question left by Valsiner in his already mentioned article (Valsiner, 2008). How to do empirical work on human development on a new key? How to research on that crucial feature - that self-reflexive intentional relating with the anticipated future?

By studying artists, their trajectories and their works of art, I have worked with an exciting perspective in empirical psychological research, through the notions of performance and performativity in development (da Rocha Lordelo, 2017, 2018, 2021). However, one does not need to study (or be him or herself) an artist to work with this perspective; artists provide, that is for sure, illustrative examples of that kind of empirical work. Taking further Valsiner's proposal of an epistemology of becoming, on a theoretical and methodological level, I propose the poetics of performing. The poetics of performing is a way of living and studying development, and I am going to take into account my own experience in order to show that.

I have previously identified and addressed a vibrant, highly productive concept of development within cultural psychology (da Rocha Lordelo, 2017). Freeman and Robinson (1990) have, now a few decades ago, argued that the idea of development (expanding its focus on childhood and specially considering adulthood) has been generally conceived in terms of already prescribed ends, as in normative models; or in terms of complete absence of ends. In contrast, the authors suggest development to be better conceived in terms of progressive transformation of ends (Freeman \& Robinson, 1990). This idea of progressive transformation of ends is consonant with recent claims of cultural psychologists, which I have already mentioned here: it is an idea which understands development as the property 
of open systems to undergo qualitative transformations, under constant relating with the environment within irreversible time (Zittoun et al., 2013). Freeman (1999) also proposes the notion of poetic construction of selfhood. Development, for Freeman and Robinson (1990, p. 61), is self-perpetuating, in a sense "that it begets itself: by being predicated neither upon preconceived ends nor the absence of ends, but upon the revision [authors's emphasis] of ends," it is a process that sows the seeds of its own perpetuation." They also claim that there are no final ends, only differences, and that crucial condition makes a difference in the person's experiential world.

And why is that poetic? In his classic treatise, Aristotle said that while History tells us what has happened, Poetry relates "what may happen" (2008, p. 35). Much later, in the twentieth century, Pareyson's formativity aesthetic theory was a relevant contribution to that discussion. He claims that art is at the same time invention and production; and that the artist must make what does not yet exist, and must therefore invent while executing (Pareyson, 2005).

While discussing poetry and the poetic construction of selfhood, Freeman (1999 p. 15) defines poiesis as the process of re-creation via imagination. That idea of construction through imagination that constitutes poetics entails the individual's permanent reconstruction (and also self-reconstruction). This is a great definition of human development.

Those movements of human reconstruction constitute, in a way, the poetics of performing. The term "performing" refers, here, to a much broader notion than the one emcompassed by the arts (as in the term "performance art"), and is rather linked to a performative turn that took place in Philosophy and Linguistics in the first half of the twentieth century. Scholars working in that paradigmatic shift started to claim there could be no radical disctintion between language and the world, for it is the words and symbols we use that establish the reality as we live it. One of the most relevant contibutions in that field comes from John Austin (1962) and his speech acts theory. His theory basically set the grounds to understanding that speaking always involves acting; the performative, as theorized by Austin and other seminal authors such as Butler (1988), also has the ability to destabilize and even colapse binary oppositions - speaking $X$ acting, world $X$ language, etc. Fighting these dichotomies has substantial implications when it comes to psychological phenomena-but that is far from the scope of this short article.

In an introductory book dedicated to the subject, Schechner (2006) explains that we can find performances in many situations (seen separately or intertwined): in daily life, sports, sex, in rituals, business situations etc., and also in the art world, of course. From this claim, it is possible to conclude that performance is a broad concept, that includes art, but does not limit itself to it. In a way, for Schechner, not everything is meant to be performance, but virtually everything can be seen as performance.

\section{Performing Motherhood}

In an autobiographical effort, I will bring my experience on becoming a mother in the previous year, through self-writings and letters, in order to illustrate the notion of poetics of performing - the poetics of mothering, in this case. There is a strong autoethnographical dimension of this study, for it seeks to understand culture in relation to a researcher's personal experiences; Tsuchimoto (2021) claims, in an article in this special issue, that previous studies have not paid sufficient attention to dealing with the developmental aspects of autoethnography. In addition, for Zittoun and Gillespie (2012), there is still little reflection 
on the possibility of treating diaries and letters as data to learn about the narrator's change and development, but they are exactly the kind of data that enables us to study these processes. Besides, looking to letters, diaries and other kinds of self-writings is a way of getting information on a situation that is constantly evolving - which is the case of experiencing motherhood-leading us methodologiccally to the observation of longitudinal, real-life events (Zittoun \& Gillespie, 2012). The data I bring here refer to letters written throughout the year of 2020, in a period of almost 10 months from first to last excerpt.

I got pregnant on June 2019, and my baby girl was born on February in 2020, 3 months after I turned 40 - and less than 1 month before the pandemic came along in my country. I must say that becoming a mother was not exactly in my plans, although I enjoyed the idea and liked being around children and caring for them. It is just that I lived a good part of my life studying, researching, teaching, working with performing arts, hanging out with friends, and I never felt something-like a kid-was missing. Eventually my partner and I discussed the subject and it seemed a good idea, and above all, an experience we would like to have together. As I was getting older, we decided it was time to try.

That prelude contextualizes the lack of a long process of expectation on getting pregnant and becoming a mother. Motherhood (and parenthood in general) is considered one of the greatest transitions through which a woman goes, from different theoretical perspectives in psychology (Baltes et al., 1980; Erikson \& Erikson, 1998; Freud, 1976a, b; Zittoun, 2012, among others). Within cultural psychology, researches have extensively charaterized the experience of motherhood in different temporalities and contexts, as well as looked at motherhood as a normative and also a non-normative event (Cabell et al., 2015; Bastos and Pontes, 2020). It is, nonetheless, important to have in mind that women who do not wish to experience motherhood go through other transitions that might be just as strong and lifechanging; moreover, some of them might also have to deal with social pressure to becoming mothers (Chaves, 2020).

Although I had not given much thought to the experience I was about to enter before I actually entered, now it is possible to look back with some distancing and realize that a lot has changed-irreversibly — and other things have not. And I am now a mother of a 1-year-old.

Perhaps precisely because I did not give it too much thought before, I realized the transition to motherhood not only through experiencing it day by day, but also by talking or writing about it. I selected excerpts from letters ${ }^{1}$ written by me to good friends from high school, to colleagues from the university and others, from the time was pregnant to a six months after my child, Irene, was born. It is importante to have also in mind another disruptive major social event that took place last year-the COVID-19 pandemic, which was declared global on March 11, 2020 (Adil et al., 2021).

\section{January 23, 2020 (To a Group of High School Friends/I was 37 Weeks Pregnant)}

And (...) as you can imagine, I am dealing with all the tasks I must finish before the baby comes - I am practically preparing to enter a nuclear shelter (laughter). Besides arranging for clothes, accessories, making room for all these novalties, I am renovating an apartment my parents helped me buy - in my mother's building - after havind sold my own place. A lot of going to the notary's office, bank transactions,

\footnotetext{
1 These writings are actually e-mails, but are written in a similar way of traditional letters.
} 
construction material stores... all this pushing the big belly. That's how it is. I will probably stay in my place for some more weeks, because it is unlikely that the renovation is done before giving birth. But renovation and birth are two events we cannot control, in general, so who knows? Maybe it is enough time to move in.

It is interesting to read that excerpt after 1 year. I told my friends I felt I was preparing to enter a nuclear shelter. That feeling stayed with me during at least 3 months after Irene was born; naturally, the pandemic surely contributed to that. Anyway, my baby was in the center of my daily concerns and responsibilities during that time. Another interesting thing is that I used to think - and came to confirm that - about motherhood as an experience that makes you lose control over things-time, sleep, leisure time, and so on.

\section{March 17, 2020 (To the same Group of Friends/Irene was Exactly 1 Month Old)}

Today Irene is one month old! If we were in a kind of quarantine, imagine now... I will be bored soon. But one can never be too careful, right?

(...)

This month went by actually fast. We are doing fine, getting to know and learn from each other.

When Irene turned one month, I wrote the same friends again-this time, my concerns were a little different. I felt that, because I was spending too much time at home nursing the baby, I would eventually feel bored. But I had already realized something else: with so consuming parenting demands, it felt like time went by fast. It was the opposite of boredom.

\section{April 16, 2020 (To a Colleague who was 21 Weeks Pregnant at the Time/Irene was 2 Months Old)}

A third pair of arms is important in the first few months... and there is no time to feel lonely.

That's great! You are 21 weeks now! (...) That's lovely! And when they start kicking... oh!I started the pregnancy period not wanting to ritualize anything, nor to hiper-signifiy things; I didn't want a diaper shower, ${ }^{2}$ and bought those ecological diapers, nor baby shower... even the doula came along nearly in the end of pregnancy, when I realized I actually should ritualize a couple of things (laughter). So I guess now is when I am falling in love, living with her, watching her grow and fill each hour of the day. It's beautiful! Tomorrow Irene will be two months old.

This particular letter is interesting, because it represents a shift in the way I faced motherhood. Having become a mother recently, I was addressing a colleague who was about to become one herself; this means I could talk to her from a more experienced position, with a two-month-old baby. I wrote to my friend referring to the period I was pregnant, without great specific expectations on becoming a mom. But at that moment, with a baby in my arms for some time now, I started to feel more connected to Irene. It is also curious that I said the baby filled each hour of my day-in the month before, I noticed there was no

\footnotetext{
${ }^{2}$ In my country, a diaper shower is an event in which parents get diapers, specifically, from guests; but there are baby showers too, in which guests choose different types of gifts from a list and take it to the party.
} 
time to feel tedious. I am getting closer to a strong impression the first months of motherhood left in me: it is not exactly about being a mother; it is much more about acting; about doings things for your child. It is about performing motherhood.

\section{May 15, 2020 (To a Friend from the Art World/Irene was 3 Months Old)}

I have been saying in my letters that puerperium is in itself a sort of quarantine. In a way I am isolated since February now. But at the same time, I spend a lot of time being a mother, learning, and well, living that cycle of breastfeeding, waiting for her to burp, putting her to sleep, being there when she wakes up etc etc...

"Spending time being a mother," as I put in this last excerpt, referred precisely to the daily chores that followed one another. The specific cycle of breastfeeding (feeding, putting to burp, putting to sleep) is accomplished several times a day-and also during the night, for a newborn baby. That reinforces my impression about the performance of motherhood. But in a few months this impression would slightly change, as we will notice in a further excerpt.

These mundane duties of motherhood were progressively understood, accepted and appreciated, but I usually resisted to look at them in a romantic way. Performing motherhood can be of course overwhelming, specially in the first months, as this next piece of letter shows. I was writing to two friends from the art world with whom I had performed less than a year before the baby was born:

\section{June 14, 2020 (To Two Friends—a Couple-from the Art World)}

oh, boys, how I miss having lunch with you, guys. Like, without Irene, so that everything would be more relaxed... but the day before yesterday I dreamed that I got to the theater and the scenery of Torquatália ${ }^{3}$ was ready for me to go on stage; suddenly I looked around and a light technician was holding Irene in his arms. So, it is oficial, if she is in my dreams, it's for real!

This passage is important because it shows, in a way, how I referred to the times I was not a mother, how things were different-and I naturally felt comfortable talking about this with friends without kids. I tell my friends about a dream that curiously mixes my two roles, before and after the baby-actress-not-mother and actress-mother. And gradually, the feeling of overwhelming and novelty vanished, as I say to a friend who had recently become a mom herself:

\section{September 25, 2020 (To the Colleague who then had had her Baby in August/Irene was 7 Months Old)}

Congratulations to $\mathrm{X}$ ! One month and counting! And soon two, three... he looks so cute $(\ldots)$

So, you two must be dealing now with caring for him daily. Tough, isn't it? Little by little the feeling of novelty disappears, we gradually get into routines and understand our daily chores... but without help, it's hard.

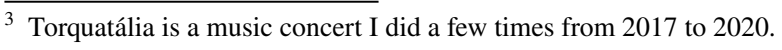


When my daughter turned six months, I told my colleague (who had then a 1-monthold baby) that soon things would get into a known pace and she (as I was) would get used to daily routines. This is how I began to feel. But these feelings on motherhood, I want to stress here, always appeared closely related to practical activities. By taking care of my baby - doing several things like bathing, dressing, changing diapers, breastfeeding, singing and lulling her - the experience of becoming a mom eventually sank in; or, as Uriko (2021) puts it, "a new level of meaningfulness: "myself as a mother"" eventually emerged. All small acts, at first considered tedious and repetitive since the baby was born, contributed to giving me a dimension of what it is to be a mom — specially of a baby (which has been my experience so far). Becoming a mother entails performing a mother.

\section{Concluding Thoughts: Performing is Becoming}

As I mentioned in the beginning, Valsiner (2008) suggested that we psychologists move from the static ontology of being - which asks "what is X?" to the epistemology of becomingwhich asks "what is X becoming"; this makes us look at human development, as a holistic, dynamic and systemic phenomenon (Wu, 2021). In this short paper, I wanted to expand on Valsiner's observations and propose the poetics of performing as a solution to the challenge of how to study that empirically. I briefly analyzed excerpts of letters I sent to friends from the moment I was pregnant, that is, about to become a mother, to aproximately seven months after my baby was born. The look over these writings showed that I gradually felt closer to my child and to actually feeling like a mother, specially through performing typically motherly chores until the point I became used to them. Performing who we are is a way of becoming, of being who we are. And each performative act, when traced, enables us to look at and understand change. Phelan (1993) theorized on performance as being, for excellence, the language of the ephemeral; even though it might feel repetitive, each time it happens-precisely because it happens in time-meanings are updated. Interestingly, Phelan (1993) also claims that to perform is to move the "as if" to the present tense "it is." Performing is a way of incessantly becoming who we are, and this is what is poetic about this never ending process.

\section{Declarations}

Ethics Approval The article is an exploration of the researcher's self-writings, so the section is not applicable.

Conflict of Interest The author declares no competing interests.

\section{References}

Adil, M. T., Rahman, R., Whitelaw, D., et al. (2021). SARS-CoV-2 and the pandemic of COVID-19. Postgraduate Medical Journal, 97, 110-116.

Aristotle (2008). Poetics. McMillan \& Co, limited.

Austin, J. (1962). How to do things with words. Oxford: Oxford University Press.

Baltes, P. B., Reese, H. W., \& Lipsitt, L. P. (1980). Life-Span Developmental Psychology. Annual Review of Psychology, 31(1), 65-110.

Bastos, A. C., Pontes, V. V., \& (orgs). (2020). Nascer não é para todas as pessoas. EDUFBA.

Butler, J. (1988). Performative Acts and Gender Constitution: An Essay in Phenomenology and Feminist Theory. Theatre Journal, Vol. 40, No. 4. (Dec., 1988), pp. 519-531. 
Cabell, K. R. \& Valsiner, J. (2014). Systematic Systemics: Causality, catalysis, and developmental cybernetics. In: K. R. Cabell \& J. Valsiner (eds.). The catalyzing mind: beyond models of causality. Annals of Theoretical Psychology, Vol. 11. New York: Springer Science.

Cabell, K. R., et al. (Eds.). (2015). Making meaning, making motherhood. (p. 1). Information Age Publishing. Annals of Cultural Psychology, v.

Chaves, S. S. (2020). Não maternidade voluntária: a dinâmica do self em circunstâncias não normativas. In: A. C. Bastos \& V. V. Pontes (orgs) (2020). Nascer não é para todas as pessoas. Salvador: EDUFBA.

da Rocha Lordelo, L. (2017). The poetics within performance art: the developmental nature of artistic creative processes. O. Lehmann, N. Chaudhary, A. C. Bastos, E. Abbey (eds.) Poetry and Imagined Worlds. Palgrave Mcmillan: Cham, Swtizerland.

da Rocha Lordelo, L. (2018). The Sublime in Relational Art: Meaning- Making Processes on the Move. In: Maria C. D. P. Lyra; Marina Assis Pinheiro. (Org.). Cultural Psychology as Basic Science Dialogues with Jaan Valsiner. 1ed.Cham: Springer, v. 1.

da Rocha Lordelo, L. (2021). Bola de Fogo: para atualizar o ancestral em nós. Em: A. Guerra (org) Corpo e(m)performance: processos de criação, Rio de Janeiro: Synergia.

Erikson, E., \& Erikson, J. M. (1998). O Ciclo de vida completo - versão ampliada com novos capítulos sobre o nono estágio do desenvolvimento. ArtMed.

Freeman, M. (1999). Culture, narrative and the poetic construction of selfhood. Journal of Constructive Psychology, 12, 99-116.

Freeman, M., \& Robinson, R. (1990). The development within: An alternative approach to the study of lives. New Ideas in Psychology, 8, 53-72.

Freud, S. (1976a). A dissolução do complexo de Édipo. In: Edição standard brasileira das obras completas de Sigmund Freud (J. Salomão, trad.) (Vol. 19). Rio de Janeiro: Imago.

Freud, S. (1976b). Sexualidade feminina. In Edição standard brasileira das obras completas de Sigmund Freud (J. Salomão, trad.) (Vol. 21). Rio de Janeiro, RJ: Imago.

Pareyson, L. (2005). Os problemas da estética. Martins Fontes.

Phelan, P. (1993). Unmarked. Politics of Performance. London; New York: Routledge.

Schechner, R. (2006). Performance studies: an introduction, 2nd edition. New York \& London: Routledge.

Tsuchimoto, T. (2021). Transfer of Specific Moment to General Knowledge: Suggestions from Cultural Developmental Autoethnography and Autoethnographic Trajectory Equifinality Modeling. Human Arenas, this issue, $\mathrm{x}, \mathrm{x}$.

Uriko, K. (2021). Are we still at the beginning of our study of motherhood and mother-child bond? Human Arenas, this issue, $\mathrm{x}, \mathrm{x}$.

Valsiner, J. (2008). Open intransitivity cycles in development and education: Pathways to synthesis. European Journal of Psychology of Education, Vol. XXIII, 2, 131-147.

$\mathrm{Wu}$, A. (2021). Transitions and psychology as a developmental science: building up on Jaan Valsiner's workbond? Human Arenas, this issue, $\mathrm{x}, \mathrm{x}$.

Zittoun, T. (2012). Life-Course: A Socio-Cultural Perspective. Valsiner, J. (Ed.). The Oxford Handbook of Culture and Psychology. New York: Oxford University Press. Pp. 513-535.

Zittoun, T., \& Gillespie, A. (2012). Using Diaries and Self- writings as Data in Psychological Research. In: Emily Abbey and Seth Surgan (eds). Emerging Methods in Psychology. New Jersey: Transaction Publishers.

Zittoun, T., Valsiner, J., Vedeler, D., Salgado, J., Gonçalves, M. \& Ferring, D. (2013). Human Development in the lifecourse. Melodies of Living. Cambridge: Cambridge University Press.

Publisher's Note Springer Nature remains neutral with regard to jurisdictional claims in published maps and institutional affiliations. 